Cahiers $d u$ MONDE RUSSE

\section{Cahiers du monde russe}

Russie - Empire russe - Union soviétique et États indépendants

$51 / 4 \mid 2010$

Sciences humaines et sociales en Russie à l'Âge d'argent

\title{
Leonid Livak, The Jewish Personna in the European Imagination
}

\section{Boris Czerny}

\section{OpenEdition}

\section{Journals}

Édition électronique

URL : https://journals.openedition.org/monderusse/7449

DOI : 10.4000/monderusse. 7449

ISSN : $1777-5388$

Éditeur

Éditions de l'EHESS

\section{Édition imprimée}

Date de publication : 25 novembre 2010

Pagination : 821-823

ISBN : 978-2-7132-2316-7

ISSN : $1252-6576$

\section{Référence électronique}

Boris Czerny, "Leonid Livak, The Jewish Personna in the European Imagination », Cahiers du monde russe [En ligne], 51/4 | 2010, mis en ligne le 09 décembre 2011, consulté le 03 septembre 2022. URL http://journals.openedition.org/monderusse/7449; DOI : https://doi.org/10.4000/monderusse.7449

Ce document a été généré automatiquement le 3 septembre 2022

Tous droits réservés 


\title{
Leonid Livak, The Jewish Personna in the European Imagination
}

\author{
Boris Czerny
}

\section{RÉFÉRENCE}

Leonid LIVAK, The Jewish Personna in the European Imagination. A Case of Russian

Literature. Stanford: Stanford University Press, 2010, 498 p.

1 «Le Roi est mort. Vive le roi ! ». La formule rituelle, prononcée lors de l'annonce de la mort d'un roi de France et de la montée sur le trône d'un nouveau souverain, peut désormais être appliquée au concept de littérature «russe juive». En effet, le livre de Leonid Livak devrait, selon nous, mettre un point final aux débats sur l'existence d'une littérature « juive russe » et l'appartenance d'écrivains juifs, d'origine juive ou de culture juive, à cette création littéraire qui, comme le souligne l'auteur dans la conclusion, n'a jamais existé en tant que littérature indépendante du fait même de sa double allégeance aux cultures juive et russe et, plus exactement, européenne.

2 Dans la conclusion (p.353-368) de l'ouvrage qui comporte quatre parties [ $"$ The Generative Model of the 'Jews' ", "How Gogol's Iankel' Is Made ", "The Discreet Pleasures of Liberalism», "Concerto for Flute Without Orchestra»], auxquelles il convient d'associer la très complète bibliographie, Livak reprend point par point la théorie sur la littérature juive russe élaborée par Šimon Markiš (1931 -2003) ${ }^{1}$. Le choix de Markiš est judicieux. En effet, le fils du célèbre poète yiddish, Perec Markiš, a participé activement dans les années 1980-1990 à la découverte, ou redécouverte, de grands noms d'écrivains et poètes juifs de langue russe et, depuis près de trente ans, ses travaux servent de base de réflexion à toutes les études sur la littérature juive russe. Mais, comme le montre l'auteur, la principale ambiguïté des études de Markiš réside dans la grande confusion entre l'origine - religieuse et/ou culturelle - de certains écrivains et le contenu de leur œuvre qui est jugé et classé en fonction précisément de cette origine, mais aussi de la langue utilisée, de la position de l'écrivain à l'intérieur d'un monde juif 
conçu comme un ensemble uniforme et un corps unique ${ }^{2}$. Mais, et c'est bien là la principale critique adressée par Livak à Markiš, la focalisation sur l'écrivain a complètement occulté l'élément peut-être le plus important de l'expression « littérature juive russe », à savoir la littérature en tant que processus (p. 363).

Le titre de l'ouvrage est révélateur de la démarche de l'auteur. L'accent est volontairement mis sur le «juif» en tant que personnage - Jewish Personna - et sur la littérature russe (et non juive) - en langue russe, qui est à juste titre établie dans sa corrélation avec les autres littératures et cultures européennes. La définition précise, dans la première partie, des motifs caractérisant les « juifs » dans l'imagerie européenne, permet d'établir leur rôle littéraire. Cette mise en évidence d'« invariants littéraires juifs » dans des romans et récits d'écrivains russes comme Gogol', Turgenjev et Čehov et dans celles d'écrivains " juifs », Babel' et Jurij Fel'cen, permet non seulement d'opérer des rapprochements subtils entre des grandes œuvres de la littérature européenne comme Ivanhoé de Walter Scott, La Case de l'Oncle Tom d'Harriet Beecher Stowe, L'Aveu de Maupassant ou À la recherche du temps perdu de Proust, mais aussi d'établir des connexions entre des écrivains étiquetés « juifs » et " russes » comme Babel', Gogol' et Čehov par exemple. Ainsi, la lecture parallèle de Skripka Rotšil'da [Le Violon de Rothschild] de Čehov et de Probuždenie [Le Réveil] de Babel', et leur juxtaposition avec le texte de Richard Wagner Das Judenthum in der Musik [Le Judaïsme dans la musique], permet à l'auteur non seulement de relativiser l'apparent contenu judéophile du récit de Čehov, mais aussi d'éclairer la volonté de Babel' d'intégrer la littérature européenne en cessant d'être juif (en tant qu'écrivain), mais en devenant juif (en tant que personnage de sa propre autobiographie fictive). Comme le démontre Livak - et c'est là le résultat le plus remarquable de son étude -, le recours à un patrimoine commun (The Jewish Personna in the European Imagination) fut pour les écrivains russes un moyen d'affirmer leur appartenance à la littérature européenne et pour les auteurs juifs un procédé favorisant leur " déjudaïsation ». Cet apparent paradoxe est explicité à l'aide des termes " adjuvant " (helper) et "opposant» (foe), empruntés à La Sémantique des contes de Vladimir Propp. Cet emprunt, qui rehausse le caractère fictionnel des juifs en tant que création littéraire, relativise tout autant le caractère judéophobe de certaines œuvres comme Taras Bul'ba, dans lesquelles le juif peut jouer le rôle positif d'adjuvant, que des textes à tonalité explicitement judéophile reprenant comme du "papier carbone " (carbon copy) des descriptions jugées négatives dans d'autres contextes (p. 222). Les remarques sur les limitations artistiques résultant de l'emploi politiquement correct de evrej (terme neutre pour signifier le juif en russe) au détriment de žid (mot connoté négativement pour désigner le juif dans la littérature à partir des années 1860) illustrent la ligne générale d'un ouvrage d'une très haute tenue scientifique qui n'hésite pas à bousculer les conventions et les idées toutes faites.

Une telle démarche iconoclaste n'est pas sans risque. L'auteur cède trop facilement, selon nous, à une explication " psychologique » pour présenter certains faits littéraires. Les limites entre les sphères relevant de l'intime - par exemple les relations entre Pauline Viardot et Turgenev - et le domaine littéraire sont franchies avec une certaine audace, louable mais dangereuse. En l'absence de tout témoignage, il est difficile d'apprécier dans quelle mesure un écrivain se projette dans son œuvre et, dans le cas présent, utilise les «juifs» en tant que médium d'expression de sa propre sexualité. De même, la détermination de la judéité de certains personnages uniquement à partir de quelques indices à valeur métonymique - yeux noirs ou lunettes, cheveux frisés, nom, comme celui d'un personnage de Babel' s'appelant Česnokov, ce qui serait une allusion à l'odeur 
d'ail (en russe česnok) caractéristique de la cuisine juive - n'est pas toujours pertinente. Mais ces quelques « imperfections » sont en fait l'illustration du caractère novateur d'un ouvrage essentiel qui démontre de manière éclatante les limites de l'expression « littérature juive russe ».

5 «Le Roi est mort! Vive le roi !». L'annonce de la disparition de la littérature russe juive - en tant que mythe littéraire - est porteuse d'espoir. En effet, et ce n'est pas le moindre des paradoxes, tout en relevant la dimension fictionnelle et fonctionnelle des personnages juifs, par sa méthode d'investigation Leonid Livak parvient à créer une œuvre profondément juive par l'esprit et par la forme. The Jewish Personna in the European Imagination est une invite à lire et relire les œuvres comportant des personnages juifs, afin de déterminer leur appartenance à l'imaginaire collectif européen. Cette étude est vraiment un très grand livre.

\section{NOTES}

1. Pour les articles publiés dans les Cahiers du Monde russe, voir : http ://ecoledoctorale.sciencespo.fr/publications/calb/8/Simon_Markish.pdf

2. Š. Markiš a souvent repris le même schéma pour caractériser la littérature juive-russe. Cependant dans ses derniers travaux il est possible de noter certaines inflexions. Dans l'introduction du livre Rodnoj golos, Kiev : Dukh i Litera, 2001, la création littéraire juive-russe est définie en termes de paysage. Nous avons repris et développé récemment ce concept de "paysage " (exotique) pour arriver à une conclusion opposée à celle de Markiš et donc très proche des déductions de L. Livak. Pour nous la seule réalité d'une œuvre "russe-juive » est avant tout littéraire et non identitaire. Ces travaux La Steppe de Tchékhov, Nouvelles lectures et "Une Approche exotique de la littérature russe-juive » sont en cours de publication. L'étude du paysage donne des résultats recoupant les remarques de L. Livak sur le contenu des œuvres de Čehov et Gogol' et tout particulièrement l'identification de Taras-Bul'ba à Moïse (p. 135-136). La prise en compte de l'image des "briques " [cf. Taras Bul'ba's trip to Warsaw in a carriage transporting bricks (p. 136)] qui est aussi présente au tout début de La Steppe de Čehov donne au voyage du jeune Egoruška une dimension biblique. 